

\title{
Carboxylate- and Phosphonate-Modified Polyethylenimine: Toward the Design of Actinide Decorporation Agents
}

Florian Lahrouch, Bruno Siberchicot, Jeanne Fèvre, Laurane Léost, Jean Aupiais, Pier Lorenzo Solari, Christophe den Auwer, Christophe Di Giorgio

\section{To cite this version:}

Florian Lahrouch, Bruno Siberchicot, Jeanne Fèvre, Laurane Léost, Jean Aupiais, et al.. Carboxylateand Phosphonate-Modified Polyethylenimine: Toward the Design of Actinide Decorporation Agents. Inorganic Chemistry, 2020, 59 (1), pp.128-137. 10.1021/acs.inorgchem.9b02014 . hal-02533932

\section{HAL Id: hal-02533932 \\ https://hal.univ-cotedazur.fr/hal-02533932}

Submitted on 6 Apr 2020

HAL is a multi-disciplinary open access archive for the deposit and dissemination of scientific research documents, whether they are published or not. The documents may come from teaching and research institutions in France or abroad, or from public or private research centers.
L'archive ouverte pluridisciplinaire HAL, est destinée au dépôt et à la diffusion de documents scientifiques de niveau recherche, publiés ou non, émanant des établissements d'enseignement et de recherche français ou étrangers, des laboratoires publics ou privés. 


\title{
Carboxylate and Phosphonate Modified Polyethyleneimine: Towards the Design of Actinide Decorporation Agents.
}

\author{
Florian Lahrouch $^{\dagger /}$, Bruno Siberchicot ${ }^{\ddagger}$, Jeanne Fèvre ${ }^{\dagger}$, Laurane Leost ${ }^{\dagger}$, Jean Aupiais ${ }^{\ddagger}$, Pier Lorenzo \\ Solari ${ }^{\S}$, Christophe Den Auwer ${ }^{\dagger *}$ and Christophe Di Giorgio ${ }^{\dagger^{* *}}$ \\ ${ }^{\dagger}$ Université Côte d'Azur, CNRS, Institut de Chimie de Nice, UMR 7272, 06108 Nice, France \\ $\$$ CEA, DAM, DIF, F-91297 Arpajon cedex, France \\ ${ }^{\S}$ Synchrotron SOLEIL, L'Orme des Merisiers, Saint-Aubin, BP 48, F-91192 Gif-sur-Yvette, France \\ / present address : Sorbonne Université, IMPMC UMR 7590, Paris, France \\ * christophe.denauwer@univ-cotedazur.fr \\ * christophe.di-giorgio@univ-cotedazur.fr
}

\begin{abstract}
Plutonium $(\mathrm{Pu})$ is an anthropogenic element involved in the nuclear industry cycle. Located at the bottom of the periodic table within the actinide family, it is a chemical toxic but also a radiological toxic, regardless of isotopy. After nearly 80 years of plutonium industrialization, it has become clear that inhalation and wounds represent the two main ways a person may become contaminated after an accident. In order to reduce the deleterious health effects of $\mathrm{Pu}$, it is crucial to limit chronic exposure by removing it or preventing its incorporation into the body. Diethylene triamine penta acetic acid (DTPA) has emerged as the gold standard for plutonium decorporation, although it suffers from very short retention time in serum. Other molecules like the hydroxypyridonate family with high chemical affinity have also been considered. We have been considering alternative polymeric chelates and, in particular, polyethyleneimine (PEI) analogues of DTPA (carbonate or phosphonate version), which may present a real breakthrough in plutonium decorporation not only because of their higher loading capacity, but also because of their indirect vectorization properties correlated with a specific biodistribution into the lungs, bone, kidney or liver.

In the first part of this forum article, new data on the structural characterization of the complexation of $\mathrm{Pu}(\mathrm{IV})$ with polyethyleneimine methylphosphonate (PEI-MP) were obtained using the combination of EXAFS spectroscopy (Extended X-Ray Absorption Fine Structure) and $a b$ initio Molecular Dynamics calculations (AIMD). The use of thorium (Th) as a Pu chemical
\end{abstract}


surrogate is also discussed because its unique oxidation state is +IV in solution. In the second part of the paper, we put this new set of data on PEI-MP-Pu in perspective with the use of the PEI platform to complex Th(IV) and Pu(IV). Uptake curves of Th(IV) with PEI-MC, PEI-MP and DTPA are compared and ab initio Molecular Dynamics date are discussed. 


\section{INTRODUCTION}

Since the end of the Second World War, the development of civil and military nuclear industry in countries of the northern hemisphere has brought some new issues in terms of environmental impact, legacy and long-term management, defense and non-proliferation. The Chernobyl accident in April 1986 and more recently the Fukushima accident in March 2011 have had a major impact in terms of energetic policies in various countries, mostly in the West, because of the decrease in social acceptance of civil nuclear power. ${ }^{1}$ Forensics and possible misuse of nuclear materials for terrorism is also being questioned lately. In 2017, the Nobel Peace Prize was given to ICAN (International Campaign to Abolish Nuclear weapons) demonstrating the growing concern about the former Cold War atomic race and non proliferation. Plutonium $(\mathrm{Pu})$ is an issue of both nuclear weapon stockpiles, forensics and energy sources of nuclear fuel. Furthermore, plutonium is probably the element associated with most societal questioning and fear. In addition, atomic tests performed in atmospheric conditions from 1945 (USA) to 1980 (China) have deposited several tons of radionuclides with highly anisotropic repartition throughout the surface of the planet. It is for instance approximately $6.52 .10^{15} \mathrm{~Bq}$ (i.e. $\approx 3$ tons) of ${ }^{239} \mathrm{Pu}$ that was released in the atmosphere during the second half of the $20^{\text {th }}$ century. ${ }^{2}$

In environmental conditions, plutonium is mostly present at the +IV oxidation state under soluble and/or colloidal forms (although oxidation states $+\mathrm{III}$ and $+\mathrm{V}$ must not be excluded in reducing or oxidative conditions, respectively). Given the severe chemical and radiotoxicity of all isotopes of plutonium, its handling, utilization and possible accidental dispersion raises public health issues especially in the case of internal contamination. It was within the framework of the Manhattan Project $(1942$ - 1946) that the investigation of the health effects associated with radiochemistry and weapons production was initiated. In 1943, the same year as the construction of the full-scale plutonium production reactor (Hanford B reactor, WA, USA), the University of Rochester was commissioned by the Atomic Energy Commission to assess the potentially deleterious effects of atomic energy production on human health. In 1962, Professor Harold C. Hodge created the first Society of Toxicology (SOT). ${ }^{3}$

After nearly 80 years of plutonium industrialization, inhalation and wounds represent the two main entryways of accidental contamination. ${ }^{4}$ It is important to note that generally speaking plutonium (and thorium) is not naturally excreted from the body because its retention time is longer than human life expectancy. After contamination, the blood system acts as the major distribution vector of plutonium to organs ${ }^{5}$ and the kinetics of this transfer is relatively fast because 1 day after contamination less than $1 \%$ of injected Pu is still in the serum. ${ }^{6}$ In this case, the soluble fraction of plutonium as well as the smallest $\mathrm{Pu}$ particles are able to pass into the blood 
system. ${ }^{7}$ The skeleton and liver are affected by the retention of plutonium although they exhibit differences in their biodistribution. ${ }^{6}$ The soluble phase has a strong affinity with the highly vascularized hematopoietic marrow located in the bones ${ }^{8}$ and for the ferric proteins such as ferritin ${ }^{9}$, largely present in liver. The colloidal forms of plutonium are managed by the reticuloendothelial system also located in the liver and bones. ${ }^{5}$ Furthermore, the continuous irradiation of internal tissues caused by the severe radiotoxicity of plutonium is at the origin of serious tissue damage and can trigger bone and liver cancers or leukaemia. 10,11 In the case of inhalation, the insoluble portion as well as the colloids which are not able to translocate to the blood compartment remain trapped into alveolar macrophages which serve as a reservoir for actinide retention. ${ }^{12}$ To reduce the deleterious health effects of $\mathrm{Pu}$, it is crucial to remove or prevent incorporation in the body in order to limit the long-term chronic exposure. However, the partial hydrolysis of actinides at physiological $\mathrm{pH}$, their interactions with biologic matter (proteins, metabolites, bone matrix, liver, macrophages, etc.) or the abundance of endogenous cations (Fe(III), $\mathrm{Ca}(\mathrm{II})$ ) make the specific actinide extraction from the biological media difficult. Additionally, their different chemical properties require the development of specific chelators adapted to each actinide.

First attempts of Pu human decorporation treatments used dietary modification or hormones. ${ }^{13}$ But this proved to be unsuccessful. Painter et al. administrated sodium citrate to $\mathrm{Pu}(\mathrm{IV})$ contaminated dogs and observed an increase of urinary $\mathrm{Pu}(\mathrm{IV})$ excretion. ${ }^{14}$ Dimercaptopropanol (BAL), usually used to cure the heavy metal poisoning (lead, mercury or bismuth), was for a time envisioned for plutonium and radium decorporations. ${ }^{14}$ Eventually, BAL was revealed to be more effective for polonium chelation. ${ }^{15}$ Amino carboxylate acids started to be studied for actinide chelation in the 50's. First, ethylene diamine tetra acetic acid (EDTA) which forms a stable complex with $\mathrm{Pu}(\mathrm{IV})(\log \beta=26.4)^{16}$ was tested as calcium salts $\left(\mathrm{CaNa}_{2}\right.$-EDTA) but its lack of selectivity for $\mathrm{Pu}(\mathrm{IV})$ prevented its use. ${ }^{17}$ Then the diethylene triamine penta acetic acid (DTPA) emerged as a powerful $\mathrm{Pu}(\mathrm{IV})$ chelator. The complexation site formed by 5 oxygen and 3 nitrogen atoms exhibits a high chelating constant for plutonium (IV) $(\log \beta=36.36, \mathrm{I}=0,1 \mathrm{M}) .{ }^{18,19}$ Studies on mice showed that injections of Ca-DTPA, less than one hour after contamination, permit the urinary excretion of around $60 \%$ of the inner Pu(IV). ${ }^{20}$ Also DTPA modifies the Pu(IV) biodistribution limiting the bone and liver retention. ${ }^{20}$ Still used today, DTPA injected as Ca(II) or $\mathrm{Zn}$ (II) salt form is considered as the most effective chelating agent for promoting $\mathrm{Pu}(\mathrm{IV})$ excretion ${ }^{21}$. However, this molecule is severely limited because of its weak selectivity towards $\mathrm{Pu}$ and its narrow distribution within the body, $22-25$ being active mainly in serum ${ }^{20,26}$ and for a short period of time (from a report of Breustedt and coworkers, $400 \mathrm{~min}$ after injection, less than $1 \%$ of free DTPA remains in the blood compartment ${ }^{27}$ ). As already mentioned above, although the retention time of $\mathrm{Pu}(\mathrm{IV})$ in serum is less than a few hours, a remedy is needed for the fraction 
which does not enter into circulation, i.e. lung and their macrophages, or go beyond the blood system to target bone or liver. ${ }^{6}$

Modern research on new chelating functions with affinity for $\mathrm{Pu}(\mathrm{IV})$ and other actinides such as Am(III) or $\mathrm{Np}(\mathrm{V})$ lead to the development of catecholate (CAM) and hydroxypyridonate (HOPO) templates inspired by the siderophore family. ${ }^{28}$ These functional groups attached to spatially suitable molecular backbones to form multidentate chelating agents were largely studied by Raymond and Durbin research groups. Among the developed ligands, the octadentate 3,4,3LI(1,2-HOPO) emerged as a lead candidate for actinide decorporation therapy forming with $\mathrm{Pu}(\mathrm{IV})$ very stable complexes. ${ }^{29}$ The first in vivo studies showed that after the mice were contaminated, the 3,4,3-LI(1,2-HOPO) ligand was able to modify the biodistribution of Pu(IV), $\mathrm{Am}(\mathrm{III})$ and $\mathrm{Np}(\mathrm{V})$ and to drastically reduce bone, liver and soft tissues retention. ${ }^{30}$ 3,4,3-LI(1,2HOPO $)$ is also well tolerated in rats at very high doses $\left(100 \mu \mathrm{mol} \mathrm{kg}^{-1}\right.$ day $\left.^{-1}\right)$ for 28 days of daily oral administration. ${ }^{31}$ Moreover, an in vitro study showed that the 3,4,3-LI(1,2-HOPO) ligand does not disturb the activity of human liver microsomes (pool composed of phenacetin, bupropion, diclofenac, mephenytoin, bufuralol and testosterone), it is neither sensitive to the enzymatic oxidation occurring in human plasma nor to the acidic conditions present in the gastro-intestinal tract.32 Moreover, the 3,4,3-LI(1,2-HOPO) also seems able to form stable complexes with a large variety of actinides. ${ }^{33}$

So far, the development of these molecular strategies has proven very efficient in optimizing the affinity constants with actinides. But this strategy somehow finds its limitations when the actinide element is already out of the blood system or incorporated into the target organs. An alternative to this molecular strategy would be to enhance organ tropism using vectorization of molecular chelating agents. Some formulations have been seen to promote extra-blood system biodistribution and to facilitate administration. This is the case for the lipophilic form of DTPA ${ }^{34-}$ 37 or Nano-DTPA ${ }^{38}$, which consists of encapsulating DTPA with zinc acetate and other adjuvants. The latter was tested on dogs in order to decorporate Am(III). ${ }^{39}$ Liposomal forms of DTPA were recently considered using polyethylene glycol PEG to enhance the retention time and the biodistribution of DTPA.40-42

Our research group is focusing on polymeric chelates and more particularly on polymeric analogues of DTPA, which may represent a real breakthrough in the actinide decorporation field because of their higher loading capacity (larger abundance of chelating sites per mg of polymer that could enhance uptake rates), but mostly because of their indirect vectorization properties correlated with a specific biodistribution into the lungs, bone, kidney or liver. ${ }^{43}$ This tropism is mainly structural, i.e. polymers are retained in the main organs due to a size effect and/or enhanced binding properties (ionic, hydrogen, van der Waals) and are more prone to activate phagocytosis from macrophages. Our polymeric structural analogues of DTPA are therefore based 
on the well-known branched polyethyleneimine (bPEI) molecule either functionalized with methylcarboxylates (true higher homologue) or with methylphosphonates (used as another class of chelating groups). Studies performed with alkylcarboxylated PEI ${ }^{44}$ or succinamic acid PEI 45 revealed that anionization of PEI resulted into improved biocompatibility and decreased the cytotoxicity of the related modified polymers. Recently, we have reported that the functionalized polyethyleneimine methylcarboxylate (PEI-MC, Figure 1a) is able to complex Pu(IV) and Th(IV) by forming the same complexation site as the DTPA. ${ }^{46}$ PEI-MC is also able to complex U(VI) under physiological model conditions. ${ }^{47}$ As for the polyethyleneimine methylphosphonate (PEI-MP, Figure $1 \mathrm{~b}$ ), it is known to seek out bone macromolecules and was at one time considered for ${ }^{117 \mathrm{~m} S n}$ or 99mTc complexation for bone cancer imagery and scintigraphy.48 Biodistribution and biokinetic studies have shown that the PEI-MP is distributed to the bones and liver with a biological half time of less than $30 \mathrm{~min}$ in the liver and more than $4 \mathrm{~h}$ in the bone.49 PEI-MP was also investigated for its capacity to complex U(VI) in pseudo physiological conditions. 50

This forum article is formally divided in two parts. First, we present new results on the structural characterization of the complexation of $\mathrm{Pu}$ with polyethyleneimine methylphosphonate (PEI-MP) using the combination of EXAFS spectroscopy (Extended X-Ray Absorption Fine Structure) and ab initio molecular dynamics calculations (AIMD). We also discuss the use of thorium (Th) as a plutonium chemical analogue (surrogate) because its unique oxidation state is +IV in solution and also because its specific activity (for ${ }^{232} \mathrm{Th}, 4 \times 10^{3}$ Bq.g-1) makes it much easier to manipulate in the laboratory than $\mathrm{Pu}$, regardless of its isotopy. Th has frequently been reported to mimic the chemistry of plutonium at oxidation state +IV although this must always be taken with caution. ${ }^{51}$ One limitation comes from the increase of the nuclear charge that is in brief responsible for radii contraction occurring from the left to the right of the series together with relative stabilization of the 5 f orbitals. Consequently, the physical chemical properties of Pu differ slightly from that of Th, even at the same oxidation state +IV. Nevertheless, the physical chemical data for Th and $\mathrm{Pu}$ presented here represent a basic chemistry approach necessary for further biological evaluations of these modified polymers towards Pu(IV) contamination. The second part of the paper puts this new set of data on PEI-MP-Pu in perspective with the use of the PEI platform to decorporate actinides. Previous reported characterizations for both PEI-MP and PEI-MC involved in the complexation of $\mathrm{M}(\mathrm{IV})(\mathrm{M}=\mathrm{Th}$ and $\mathrm{Pu})$ are also discussed.

\section{EXPERIMENTAL SECTION}

The PEI-MP was synthetized as described in a previous study. .5

\section{Uptake curves}

The experimental conditions for the measurement of the uptake curves of PEI-MP-Th, PEI-MC-Th and DTPA-Th are described in previous reports. 46,50 
Each series of Th(IV) uptake data points was fitted to a four-parameter logistic nonlinear regression model ${ }^{52}$ representing a truncated sigmoid:

$$
y=a+\frac{(b-a)}{\left[1+\frac{E C 50^{n}}{x^{n}}\right]}
$$

where $y$ is the expected response at dosage step $x, a$ is the response at step $=0, b$ is the maximum response at infinite step, $E C 50$ is the titration point at $50 \%$ response (it also reflects the inflection point of the dose-response curve) and $n$ is the slope at the EC50.

For both systems, $a$ was kept at $5 \%$ according to the result of the blank found for Th(IV) in the absence of a chelating agent.

Extended X-ray absorption fine structure (EXAFS) of PEI-MP-Pu

\section{PEI-MP-Pu Sample preparation}

$25 \mu \mathrm{L}$ of a solution of plutonium nitrilotriacetate solution $\left([\mathrm{Pu}]=5 \times 10^{-4} \mathrm{M}, \mathrm{pH} 4\right)$ was added to $225 \mu \mathrm{L}$ of a PEI-MP solution ( $1 \mathrm{mg}^{\mathrm{mL}} \mathrm{m}^{-1}$ ) containing TBS buffer $\left(\mathrm{pH}=1.0\right.$, [TRIS] $=5 \times 10^{-5} \mathrm{M},[\mathrm{NaCl}$ ] $=15 \times 10^{-5} \mathrm{M}, \mathrm{pH}=7$ ). The final $\mathrm{pH}$ was equal to 6.5 and $\mathrm{Pu}$ final concentration equal to $5.5 \times 10^{-5} \mathrm{M}$. This corresponds to a stoichiometry of the Pu:PEI-MP monomer molar ratio of 0.02 (this large under-stoichiometry of Pu ensures that the limit complex was obtained).

\section{Data recording and processing}

EXAFS experiments at the $\mathrm{Pu} \mathrm{L}_{\mathrm{III}}$ edge were carried out on the MARS beamline of the Soleil synchrotron facility. The MARS beamline is dedicated to the investigation of radioactive materials in the hard X-ray range. Because of the low concentration of the samples, EXAFS measurements were performed in fluorescence mode using a 13-element high purity germanium detector (ORTEC) with specifically designed $200 \mu \mathrm{L}$ cells (Ets CANAPLE, Grenoble, Fr). The optics of the beamline essentially consist of a water-cooled double-crystal monochromator (FMB Oxford), which is used to select the incident energy of the X-ray beam and for horizontal focalization, and two large water-cooled reflecting mirrors (IRELEC/SESO) that are used for high-energy rejection (harmonic portion) and vertical collimation and focalization. In this case, the monochromator was set with the Si (220) crystals and the mirrors with the Pt strips. Energy calibration was performed at the Y K edge at $17038 \mathrm{eV}$.

Data processing was carried out using the ATHENA code. 53 The $\mathrm{e}_{\mathrm{o}}$ energy was identified at the maximum of the absorption edge data fitting. The signal to noise of the average spectrum $[0.016$ for 7 scans) is relatively low because of the low concentration of $\mathrm{Pu}$ in the EXAFS cells. It is estimated that the final concentration of Pu during beam time measurement was below $5 \times 10^{-5} \mathrm{M}$ because sorption of $\mathrm{Pu}(\mathrm{IV})$ onto the vessel between sample preparation and sample measurement always decreases the nominal concentration.

\section{Data fitting}


Fourier Transformation (FT) in $\mathrm{k}^{2}$ was performed between 3 and $10 \AA^{-1}$ with Hanning windows using the ARTEMIS code.53 This short range is due to the low concentration of $\mathrm{Pu}$ in the sample cell triggering strong noise on the EXAFS data $(\varepsilon(\mathrm{k})=0.016)$. Only one global amplitude factor $\mathrm{S}_{0}{ }^{2}$ and one energy threshold correction factor $\Delta \mathrm{e}_{0}$ were used for all paths. Phases and amplitudes were calculated using the FEFF6 simulation code ${ }^{54}$ included in ARTEMIS and based on the structure of the PEI-MP model monomer complexed to $\mathrm{Pu}(\mathrm{IV})$ obtained by the quantum molecular dynamics.

\section{Quantum molecular dynamics}

In the framework of DFT-PAW formalism, we used the ABINIT code ${ }^{55}$ for performing AIMD simulations on both Th and Pu-PEIMP models. For each case, we treated an isolated charged complex in a large simulation box in order to simulate the gaseous phase system. We also performed simulation in the presence of 22 water molecules in order to mimic the solvent effects. The simulations are run in the isokinetic ensemble at $298 \mathrm{~K}$ until equilibration is achieved, i.e. until the variations in pressure stabilize to an oscillatory pattern, without any long-term trend. The size of the simulation cell (20 Bohr) is chosen in order to obtain a pressure close to zero. Following equilibration, the pressure and energy are calculated by averaging over the next 2000 time steps of $0.48 \mathrm{fs}$ each. All calculations were done at the $\Gamma$ point, the centre of the Brillouin zone. For carbon, oxygen and hydrogen the pseudo potentials were taken from the ABINIT data base ${ }^{56}$, for thorium and plutonium a PAW data set was fixed and a pseudo-potential built and checked. ${ }^{57}$ The data were generated for the Perdew-Burke-Ernzerhof (PBE) exchange-correlation functional with relativistic corrections to the wave function including spin-orbit coupling. 58 We have chosen a standard actinide basis set with 7s, 6p, 6d, $5 \mathrm{f}$ in the valence band and $6 \mathrm{~s}$ and $6 \mathrm{p}$ as the semicore orbitals. In ABINIT the energy cut off is an important parameter and we investigated the convergence needed for obtaining reliable results. This cut off was fixed at $760 \mathrm{eV}$.

In plutonium systems, the presence of correlated $5 f$ electrons leads to an improper description of the electronic and the structural properties by density functional theory. To overcome these shortcomings of DFT the DFT+U (Generalized Gradients Approximation GGA+U) approach has proven to effectively correct the deficiencies. Subsequently, except for thorium (no $5 f$ electron in Th(IV)), we introduced Hubbard U and Hund's J parameters for the onsite interaction strength. Although the choice of $U$ and $J$ are debatable we used the classical values obtained for tetravalent plutonium oxide $(\mathrm{U}=4 \mathrm{eV}, \mathrm{J}=0.2 \mathrm{eV}) .59$

\section{RESULTS ON THE PEI-MP-Pu(IV) SYSTEM.}

Structural investigation of the complexation site of $\mathrm{Pu}(\mathrm{IV})$ with PEI-MP was performed with EXAFS spectroscopy (at the Pu LIII edge) in combination with AIMD simulations. EXAFS spectra 
were recorded in pseudo physiological conditions $(\mathrm{pH}=6.5,150 \mathrm{mM} \mathrm{NaCl}$ ) with a Pu: PEI-MP monomer molar ratio of 0.02 as explained in the experimental section (Figure 2a). The corresponding modulus of the Fourier transform (FT) is shown in Figure 2b. The best fit metrical parameters of the PEI-MP-Pu spectrum are displayed in Table 1 as well as comparison with data reported previously on the parent complex PEI-MP-Th. The first observation is a contraction of the first M-O coordination sphere from $\mathrm{M}=\mathrm{Th}(2.35(1) \AA)$ to $\mathrm{M}=\mathrm{Pu}(2.26(1) \AA)(\Delta=-0.09 \AA)$ in agreement with the so called actinide contraction of the ionic radii from light to heavy elements of the actinide family. Note that the number of 0 atoms was fixed arbitrarily to 9 in both cases because the adjustment of absolute coordination numbers would be meaningless in the absence of reliable model compounds (as it is often the case for $\mathrm{Pu}(\mathrm{IV}$ ) and to lesser extent for Th(IV)). In the second coordination sphere, phosphate ligation is observed for both spectra with much a larger bond distance contraction $(\Delta=-0.28 \AA$ ) from Th (3.90(1) $\AA$ ) to Pu 3.62(12) A. The great uncertainty associated with the $\mathrm{Pu}---\mathrm{P}$ distance is due to the lower signal to noise ratio of the spectrum (see experimental section), indicating that data on the second coordination sphere must be discussed with much care. Last, in the fit, the presence of a $\mathrm{Pu}---\mathrm{Cl}$ contribution is compulsory as was already observed for the fit of PEI-MP-Th. 50

$A b$ initio Molecular Dynamics simulations were performed at $298 \mathrm{~K}$ by the addition of 6 water molecules for PEI-MP*-M (M = Th, Pu, PEI-MP* = model monomeric unit of PEI-MP terminated with an ethyl and a methyl group), using ABINIT code and will be fully discussed for the comparison between Th and $\mathrm{Pu}$ in the next section. ${ }^{55}$ The monomer, presented in Figure 1a was selected to be a representative of the entire PEI-MP polymer which was obtained by the functionalization of the commercial bPEI. ${ }^{46}$ Following the natural distribution of the amines of type I, II and III (approximatively equal to 0.33/0.33/0.33 respectively in this commercial $25 \mathrm{kDa}$ branched bPEI ${ }^{60}$ ), this average model monomer is composed of three phosphonate functional groups and three nitrogen atoms. After 1 ps of equilibration, three water molecules came to complete the first cation coordination shell. A snapshot image of the PEI-MP*-Pu complex is displayed in Figure 3a. Average distances are reported in Table 3 based on radial pair distribution functions $\mathrm{g}(\mathrm{r}$ ). In Figure 4c, the first $\mathrm{Pu}-\mathrm{O}$ shell is split between $3 \mathrm{O}$ atoms at $2.20 \AA ̊$ (corresponding to the 30 atoms from phosphonate groups) and 30 at $2.50 \AA$ (for the 3 water molecules). The average equals $2.35 \AA$. $a b$ initio MD simulations also indicate that $1 \mathrm{~N}$ atom from the amino backbone of PEI-MP* is involved in the Pu coordination at $2.65 \AA$ A . But the presence of one extra N atom in the same shell is unlikely to be detected in EXAFS given the similarity of atomic numbers between $\mathrm{O}$ and $\mathrm{N}$. This contribution will not be further discussed. The second coordination shell is composed of $3 \mathrm{P}$ atoms at calculated distances of $3.55 \AA$.

Comparison between $a b$ initio MD and fitted EXAFS data brings additional information on the $\mathrm{Pu}$ coordination sphere in PEI-MP-Pu. Pu-O and Pu---P distances obtained from the EXAFS data fitting 
are less than $0.1 \AA$ different from the values obtained with $a b$ initio MD displayed in Table 2

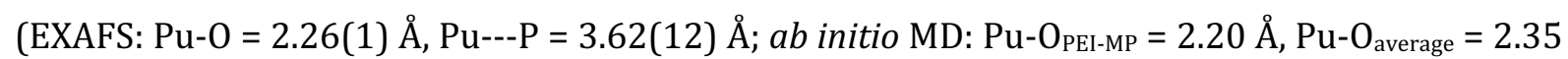
$\AA$, Pu---P $=3.55 \AA$ ). With ab initio $\mathrm{MD}$, an average model of coordination number of $30_{\mathrm{PEI}-\mathrm{MP}}+30_{\text {wat }}$ $+1 \mathrm{~N}+3 \mathrm{P}$ complexation site $(\mathrm{CN}=7+3)$ was obtained. Note that a coordination number of 7 for $\mathrm{Pu}(\mathrm{IV})$ would be at the lower limit of typical coordination numbers for An(IV) (from 8 to 12 depending on the element and its environment). ${ }^{61}$ However as PEI-MP* stands for a monomeric unit of PEI-MP terminated with an ethyl and a methyl group, the system is distorted. The corresponding nitrogen atom is further from the actinide ion than it should be. In the real polymer, this $\mathrm{N}$ atom would be closer and the coordination would be larger than 7. The EXAFS adjustment also shows a complexation site formed by phosphonate groups with 9 (fixed) $0+2.8(6) \mathrm{P}$. As mentioned before, the presence (or the absence) of additional water molecules and/or nitrogen atoms in the $\mathrm{Pu}(\mathrm{IV})$ first coordination shell is not possible to assess with EXAFS. Since the mixing of $\mathrm{O}_{\text {wat }}$ and $\mathrm{O}_{\mathrm{PEI}-\mathrm{MP}}$ triggers the average $\mathrm{Pu}-\mathrm{O}$ distance, a more in-depth comparison between EXAFS and $a b$ initio MD is difficult. Nonetheless, EXAFS spectroscopy and ab initio MD simulation exhibit $\mathrm{Pu}-\mathrm{O}$ and $\mathrm{Pu}---\mathrm{P}$ distances in the same range, confirming the implication of phosphonate groups in the complexation of $\mathrm{Pu}(\mathrm{IV})$ in a monodentate pattern.

Another point of comparison comes from literature data although almost no structure is available for organic phosphate Pu complexes. An example is given by Andreev et al. who described the structure of a Pu-nucleotide complex (deoxycytidinemonophosphate acid, $\mathrm{H}_{2} \mathrm{dCMP}$ ). ${ }^{62}$ In this structure, there are 2 independent $\mathrm{Pu}$ atoms with similar environments: three $\mathrm{O}$ atoms of the monodentate phosphates belonging to three HdCMP- anions, two bidentate nitrate anions, and two water molecules. The three 0-phosphate atoms are located at an average of $2.21 \AA$. Each phosphate group bridges three $\mathrm{Pu}$ atoms with an average $\mathrm{Pu}---\mathrm{P}$ distance equal to $3.62 \AA$. The structure of $\mathrm{Pu}\left(\mathrm{CH}_{3} \mathrm{PO}_{3}\right)_{2}$ also exhibits a bridging pattern of phosphonate groups that create $\mathrm{Pu}-\mathrm{O}$ octahedra with average Pu-O distances equal to $2.22 \AA$ A. The average $\mathrm{Pu}---\mathrm{P}$ distance equals 3.53 $\AA .63$ In the same publication the authors also describe the structure of $\mathrm{Pu}\left[\mathrm{CH}_{2}\left(\mathrm{PO}_{3}\right)_{2}\right]\left(\mathrm{H}_{2} \mathrm{O}\right)$ in which $\mathrm{PuO}_{7}$ polyhedra are formed.63 The Pu-O bond distances range from 2.18 to $2.30 \AA$ for the $\mathrm{Pu}-0$ phosphate bonds and $2.49 \AA$ A for the terminal water molecule. ${ }^{62}$ The Pu-O distance proposed in Table 1 (2.26(1) $\AA$ ) falls in the same (upper) range. The Pu---P distance in PEI-MP-Pu provided in Table 1 (3.62(12) Å) is more difficult to compare because it is impossible to know if the phosphonate groups are bridging or not. Again, the distances described in Table 1 fall within the same range as described in the above structures although all reported distances are scattered between 3.5 and $3.7 \AA$ A. One should note in any case that the steric constraint associated with the polymeric backbone of PEI-MP may play a role in extending average distances compared to smaller molecules. An overall schematic picture of the Pu coordination sphere in PEI-MP-Pu is provided in Figure 3b. 


\section{DISCUSSION ON THE PEI-MC AND PEI-MP SYSTEMS}

The uptake curves of $\mathrm{Pu}(\mathrm{IV})$ could not be recorded because of radioprotection limitations in our laboratory that make this type of measurement impossible to perform. But the uptake curves of PEI-MC-Th, PEI-MP-Th and DTPA-Th have been reported in previous publications. ${ }^{46,50}$ The curves are now compared in Figure 5abc with a new and homogenized data treatment. To avoid Th(IV) hydrolysis under these conditions, all uptake curves were recorded in the presence of two molecules of nitrilotriacetic acid (NTA) as a protecting ligand (NTA will also mimic carboxylate metabolites present in serum as citric acid or even bicarbonates). All curves are plotted as a function of the ligand concentration expressed in equivalent monomers. They all exhibit a plateau, $b$, around $100 \%$ of complexed Th(IV) attesting for a total displacement of the complexation equilibrium towards complexation at excess of chelating functions. The differences in fitting quality factors between the three curves (PEI-MP-Th : $\mathrm{R}^{2}=0.81 / \mathrm{Chi}^{2}{ }_{\mathrm{r}}=0.24$; PEI-MC-Th : $\mathrm{R}^{2}=0.95$ / $\mathrm{Chi}^{2} \mathrm{r}=0.12$; DTPA-Th : $\mathrm{R}^{2}=0.98 / \mathrm{Chi}^{2}{ }_{\mathrm{r}}=0.03$ ) originate from the polydispersity of the polymers as well as from possible loss of Th atoms during the additional step of mineralization needed for the Th titration for PEI-MP-Th and PEI-MC-Th (and not for DTPA-Th).

$E C 50$ values (we recall that $E C 50$ is the titration point at 50\% response of the ligand, therefore the lower the EC50, the higher the affinity) reported in Table 3 reflect the chelating affinity towards Th(IV). With DTPA, the $E C 50$ value $(0.13 \pm 0.01 \mathrm{mM})$ is significantly lower than for PEI-MC (1.16 $\pm 0.15 \mathrm{mM})$ and PEI-MP $(0.61 \pm 0.17 \mathrm{mM})$. If we consider the higher uncertainties related to their EC50 and the 95\% confidence interval determined from the fit, both PEI-MP and PEI-MC polymers seem to exhibit a chemical affinity for Th(IV) of the same order (within a factor of 2). On the other hand, the chemical affinity of DTPA for Th(IV) seems higher than that of PEI-MC, -MP. The affinity constant for both polymers has not been determined, but the affinity constant for DTPA-Th provided in the literature is fairly high $(\log \beta=26.6) \cdot{ }^{19}$ Another point of comparison is given by the affinity constants of the Th(IV) 1:1 complexes in Th- $\mathrm{CO}_{3}{ }^{2-}\left(\log \beta_{11}=11.0\right)$ and Th- $\mathrm{HPO}_{4}{ }^{2-}\left(\log \beta_{11}\right.$ $=10.8) \cdot 64,65$

It is to be noted that the EC50 values discussed here are a function of the monomeric concentrations within PEI-MC, -MP. First, it is important to remember that each polymer monomer can only bear a maximum (depending on the functionalization rate) of three methylcarboxylate, for PEI-MC, or three methylphosphonate, for PEI-MP. On the contrary, the functionalization degree of the reference compound is higher ( 5 complexing functions for the DTPA). This inevitably results in lower EC50 values for PEI-MC-Th and PEI-MP-Th. Second, the functionalization rate, close to $100 \%$ for PEI-MP50 and around $64 \%$ for PEI-MC47 could also explain these lower values of EC50 compared to DTPA (pure monomer).

The slope at the EC50 point ( $n$ value of the four logistic parameters fitting equation) is also a 
parameter to be considered. The slope accounts for a concentration range necessary to go from the minimal to the maximal response, i.e. the higher the slope, the narrower the concentration range. This translates as a cooperative complexation mechanism between the different complexing sites. The $n$ value for PEI-MP-Th $(1.3 \pm 0.4)$ is slightly lower than the value for PEIMC-Th $(1.8 \pm 0.3)$ and that of DTPA-Th $(2.1 \pm 0.2)$. But they all are in the same range with $n>1$, suggesting a cooperative mechanism from the functional groups. However, a direct conclusion would be adventurous. For instance, we may note that DTPA-Th has a value larger than 1 suggesting cooperativity between the complexation sites. This result is a little bit surprising for a molecular chelating agent unless polynuclear complexes may form in the experimental conditions. $A b$ initio MD simulations as described in the previous section for PEI-MP-Pu provide additional information on the structure of the coordination site in PEI-MC and PEI-MP. ${ }^{46}$ The radial pair distribution functions $\mathrm{g}(\mathrm{r})$ are displayed on Figure 4abcd and average calculated distances are displayed in Table 2. As already noted in the previous section for the EXAFS data, actinidic ionic contraction from Th to Pu is observed on all $\mathrm{g}(\mathrm{r})$. A clear shift to lower distances is also observed going from PEI-MC to PEI-MP for the first coordination sphere. But exact contraction values are difficult to give because as stated above the shape of the $\mathrm{g}(\mathrm{r})$ is not the same (the coordination spheres are not identical). Although this is not definite proof, this is in agreement with the relative decrease of EC50 values from PEI-MC to PEI-MP. Coordination sites obtained with AIMD may also be compared. In PEI-MC, the cation coordination sphere is composed of $30+3 \mathrm{~N}$ from the PEI-MC monomer and $10_{\text {wat }}$ from a water molecule $(\mathrm{CN}=7)$, very similar to that of DTPA-M $(50+3 \mathrm{~N}$, CN $=8) .{ }^{19}$ We recall that an average model of $30_{\text {PEI-MP }}+30_{\text {wat }}+1 \mathrm{~N}+3 \mathrm{P}$ complexation site $(\mathrm{CN}=7+3)$ has been obtained for PEI-MP-Pu. Note that in the case of Th, there is no $\mathrm{N}$ atom in the coordination sphere. According to the simulation, the number of water molecules able to enter in the first coordination sphere of $\mathrm{Pu}(\mathrm{IV})$ and Th(IV) is in the order: three when it is complexed to the PEI-MP, one when it is complexed to the PEI-MC, and 0 for the DTPA. This suggests again that DTPA is the most adapted chelate and this is consistent with the lowest EC50 value.

Our results confirm that the very high chemical affinity of DTPA for An(IV) is the result of very good structural arrangement around the actinide cation.19 But considering the specific biodistribution of macromolecular objects, the use of polymeric analogues of molecular chelating agents, such as PEI-MC or PEI-MP, is an interesting strategy to master body distribution and target specific organs. These polymers also have the distinctive ability of being able to complex not only $\mathrm{An}(\mathrm{IV})\left(\mathrm{Pu}(\mathrm{IV})\right.$ and $\mathrm{Th}(\mathrm{IV})$ in this report) but also actinyls such as $\left\{\mathrm{UO}_{2^{2+}}\right\}$ as well. ${ }^{47,50}$ Such approaches could then open the field for a new class of decorporating agents which may complement already existing therapies based on DTPA.

\section{CONCLUSION}


Plutonium $(\mathrm{Pu})$ is an anthropogenic element involved in the nuclear industry cycle. Located at the bottom of the periodic table within the actinide family, it is a chemical toxic but also a radiological toxic. This is why Pu decorporation is a major topic of concern in the nuclear industry. In this regard, we have taken a closer look at polymeric chelates and in particular polyethyleneimine (PEI) analogues of DTPA, which may present a real breakthrough in the plutonium decorporation strategy because of their indirect vectorization properties correlated with a specific biodistribution into the lungs, bone, kidney or liver.

In its first section, the present forum article describes the complexation site of Th(IV) and Pu(IV) with the PEI-MP polymer using a combination of $a b$ initio MD calculations and EXAFS spectroscopy in a pseudo-physiological medium. A similar complexation site for both Th(IV) and $\mathrm{Pu}(\mathrm{IV})$ was observed and involves monodentate phosphonates. The presence of $\mathrm{O}$ and $\mathrm{P}$ atoms in the first and second coordination shells of $\mathrm{M}=\mathrm{Th}(\mathrm{IV}), \mathrm{Pu}(\mathrm{IV})$ was determined via EXAFS spectroscopy and confirmed by $a b$ initio MD calculations. EXAFS best fit distances and $a b$ initio MD distances agree within 0.1 Å. Distances in both PEI-MP-Pu and PEI-MP-Th complexes are very similar to the intermolecular distances found in other Pu-phosphonate complexes. ${ }^{61,62}$ In the second part of the report, uptake curves of Th(IV) with PEI-MC, PEI-MP and DTPA were also compared. EC50 values reflect the chelating affinity towards Th(IV) and are ranked in the order DTPA $<$ PEI-MP < PEI-MC. According to the $a b$ initio MD simulation, the number of water molecules able to enter in the first coordination sphere of $\mathrm{Pu}(\mathrm{IV})$ and $\mathrm{Th}(\mathrm{IV})$ when it is complexed to the PEI-MP is equal to three, one for the PEI-MC, and 0 for the DTPA. Pair radial distribution functions $g(r)$ show a clear shift to lower distances going from PEI-MC to PEI-MP for the first coordination sphere. Although not a definite proof, this is all in agreement with the relative decrease of EC50 values from PEI-MC to PEI-MP.

Our results confirm that the very high chemical affinity of DTPA for An(IV) results in a very good fitting around the actinide cation. However, when considering the specific biodistribution of macromolecular objects, the use of polymeric chelating analogues, such as PEI-MC or PEI-MP, could be an interesting strategy to target specific sequestering compartments/organs in the case of actinide contamination. Such physical chemical approaches could then open the field for a new class of decorporating agents, complementing already existing therapies. But of course, a forthcoming development of this approach is to perform in vitro toxicity test of PEI-MC and PEIMP.

\section{ACKNOWLEDGMENTS}

EXAFS data were recorded at the SOLEIL synchrotron, the French light source of synchrotron radiation, Gif sur Yvette, France. Florian Lahrouch is very grateful to the Région PACA (Provence- 
Alpes-Côte d'Azur, France) for his PhD grant. The authors also would like to thank the Direction Générale pour l'Armement (DGA) for PhD fellowship of Jeanne Fèvre and the Commissariat à l'Energie Atomique CEA DAM DIF for financial support. 
Table 1: EXAFS best fit parameters for the PEI-MP-Tg, PEI-MP-Pu, PEI-MC-Th and PEI-MC-Pu complexes under pseudo biological conditions. Coordination numbers were fixed to 9 for the PEI-MP complex and to 8 for the PEI-MC complex (numbers in italics). Numbers in brackets are the estimated uncertainties. $\sigma^{2}$ is the Debye Waller factor of scattering path. $\mathrm{S}_{0}{ }^{2}$ is the global amplitude factor, $\mathrm{e}_{0}$ is the energy threshold. $\mathrm{R}_{\text {factor }}$ is the quality factor of the fit in $\%$ and $\mathrm{Q}$ is the reduced $C h i^{2}{ }_{r}$ factor of the fit.

\begin{tabular}{|c|c|c|c|}
\hline Sample & $1^{\text {st }}$ coordination shell & $2^{\text {nd }}$ coordination shell & $\begin{array}{c}\text { Fit } \\
\text { parameters }\end{array}$ \\
\hline $\begin{array}{l}\text { PEI-MP-Th } \\
\text { (from ref 50) }\end{array}$ & $\begin{array}{c}90 \text { at } 2.35(1) \AA \\
\sigma^{2}=0.0096 \AA^{2}\end{array}$ & $\begin{array}{c}2.8(6) \mathrm{P} \text { at } 3.90(1) \AA \\
\sigma^{2}=0.0314 \AA^{2} \\
1.8(4) \mathrm{Cl} \text { at } 3.12(2) \AA \\
\sigma^{2}=0.0092 \AA^{2}\end{array}$ & $\begin{array}{c}\mathrm{S}_{0}^{2}=1.0 \\
\mathrm{e}_{0}=-3.29 \mathrm{eV} \\
\mathrm{R}_{\text {factor }}=0.5 \% \\
\mathrm{Q}=21 \times 10^{-3}\end{array}$ \\
\hline PEI-MP-Pu & $\begin{array}{c}90 \text { at } 2.26(1) \AA \\
\sigma^{2}=0.0126 \AA^{2}\end{array}$ & $\begin{array}{c}2.2(9) \mathrm{P} \text { at } 3.62(12) \AA \\
\sigma^{2}=0.0149 \AA^{2} \\
1.4(2) \mathrm{Cl} \text { at } 3.07(3) \AA \\
\sigma^{2}=0.0055 \AA^{2}\end{array}$ & $\begin{array}{c}\mathrm{S}_{0}^{2}=0.9 \\
\mathrm{e}_{0}=4.89 \mathrm{eV} \\
\mathrm{R}_{\text {factor }}=2.9 \% \\
\mathrm{Q}=4.1\end{array}$ \\
\hline $\begin{array}{c}\text { PEI-MC-Th } \\
\text { (from ref 46) }\end{array}$ & $\begin{array}{c}50 \text { at } 2.40(1) \AA \\
\mathrm{s}^{2}=0.0038 \AA^{2} \\
3 \mathrm{~N} \text { at } 2.80(2) \AA \\
\mathrm{s}^{2}=0.0360 \AA^{2}\end{array}$ & $\begin{array}{c}5 \mathrm{C}_{\alpha} \text { at } 3.42(1) \AA \\
\mathrm{s}^{2}=0.0086 \AA^{2} \\
9 \mathrm{C}_{\beta} \text { at } 3.58(2) \AA \\
\mathrm{s}^{2}=0.0086 \AA^{2} \\
2.5(5) \mathrm{Cl} \text { at } 3.88(2) \AA \\
\mathrm{s}^{2}=0.0091 \AA^{2}\end{array}$ & $\begin{array}{c}\mathrm{S}_{0}^{2}=1.0 \\
\mathrm{e}_{0}=6.26 \mathrm{eV} \\
\mathrm{R}_{\mathrm{factor}}=1.0 \% \\
\mathrm{Q}=0.05\end{array}$ \\
\hline $\begin{array}{c}\text { PEI-MC-Pu } \\
\text { (from ref 46) }\end{array}$ & $\begin{array}{c}50 \text { at } 2.34(1) \AA \\
\mathrm{s}^{2}=0.0093 \AA^{2} \\
3 \mathrm{~N} \text { at } 2.66(2) \AA \\
\mathrm{s}^{2}=0.0171 \AA^{2}\end{array}$ & $\begin{array}{c}5 \mathrm{C}_{\alpha} \text { at } 3.38(1) \AA \\
\mathrm{s}^{2}=0.0116 \AA^{2} \\
9 \mathrm{C}_{\beta} \text { at } 3.45(2) \AA \\
\mathrm{s}^{2}=0.0116 \AA^{2}\end{array}$ & $\begin{array}{c}\mathrm{S}_{0}{ }^{2}=1.0 \\
\mathrm{e}_{0}=5.52 \mathrm{eV} \\
\mathrm{R}_{\text {factor }}=2.1 \% \\
\mathrm{Q}=0.022\end{array}$ \\
\hline
\end{tabular}


Table 2: Average interatomic distances calculated by ab initio MD for the hydrated model of PEI-MP* and PEI-MC* (from ref 46) complexes with Th(IV) and Pu(IV).

\begin{tabular}{cccc}
\hline Sample & An(IV)-0 & An(IV)-N & An(IV)-P \\
\hline PEI-MP*-Pu & $\begin{array}{c}30 \text { at } 2.20 \AA\left(\mathrm{O}_{\text {PEI-MP }}\right) \\
30 \text { at } 2.50 \AA\left(\mathrm{O}_{\text {water }}\right)\end{array}$ & $1 \mathrm{~N}$ at $2.65 \AA$ & 3 P at $3.55 \AA$ \\
\hline PEI-MP*-Th & $\begin{array}{c}30 \text { at } 2.15 \AA\left(\mathrm{O}_{\text {PEI-MP }}\right) \\
30 \text { at } 2.35 \AA\left(\mathrm{O}_{\text {water }}\right)\end{array}$ & - & $3 \mathrm{P}$ at $3.45 \AA$ \\
\hline PEI-MC*-Pu & $\begin{array}{c}30 \text { at } 2.22 \AA\left(\mathrm{O}_{\text {PEI-MC }}\right) \\
10 \text { at } 2.28 \AA\left(\mathrm{O}_{\text {water }}\right)\end{array}$ & $3 \mathrm{~N}$ at $2.68 \AA$ & - \\
\hline PEI-MC*-Th & $\begin{array}{c}30 \text { at } 2.33 \AA\left(\mathrm{O}_{\text {PEI-MC }}\right) \\
10 \text { at } 2.32 \AA\left(\mathrm{O}_{\text {water }}\right)\end{array}$ & $3 \mathrm{~N}$ at $2.74 \AA$ & - \\
\hline
\end{tabular}

Table 3: Best fit parameter obtained from the four-parameter logistic equation (eq1) with a is the response at step $=0, \mathrm{~b}$ is the maximum response at infinite step, EC50 is the titration point at $50 \%$ response, $\mathrm{n}$ is the slope at the steepest part of the curve. $\mathrm{R}^{2}$ and $\mathrm{Chi}_{\mathrm{r}}{ }^{2}$ are the quality factors of the fit.

\begin{tabular}{cccccc}
\hline & $a(\%)$ & $b(\%)$ & $E C 50(\mathrm{mM})$ & $\mathrm{n}$ & Fit parameters \\
\hline PEI-MP-Th & 5 & $97 \pm 13$ & $0.61 \pm 0.17$ & $1.32 \pm 0.35$ & $\begin{array}{c}\mathrm{R}^{2}=0.81 \\
\mathrm{Chi}^{2} \mathrm{r}=0.24\end{array}$ \\
DTPA-Th & 5 & $105 \pm 3$ & $0.13 \pm 0.007$ & $2.09 \pm 0.23$ & $\begin{array}{c}\mathrm{R}^{2}=0.98 \\
\mathrm{Chi}^{2}=0.03\end{array}$ \\
PEI-MC-Th & 5 & $110 \pm 9$ & $1.16 \pm 0.15$ & $1.78 \pm 0.26$ & $\begin{array}{c}\mathrm{R}^{2}=0.95 \\
\mathrm{Chi}^{2}{ }_{\mathrm{r}}=0.12\end{array}$ \\
\hline
\end{tabular}


a)

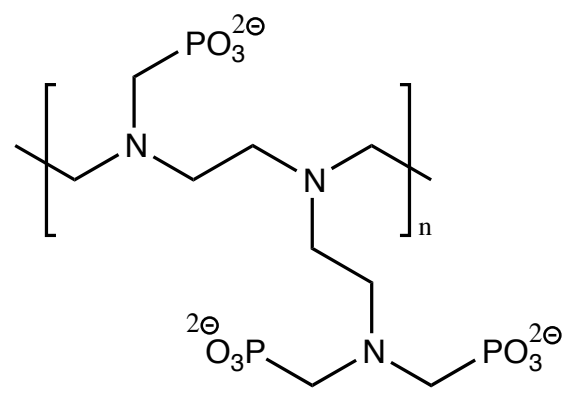

b)



Figure 1ab: Chemical scheme of the monomer of PEI-MP (a) and PEI-MC (b) polymers with an arbitrary charge level. 

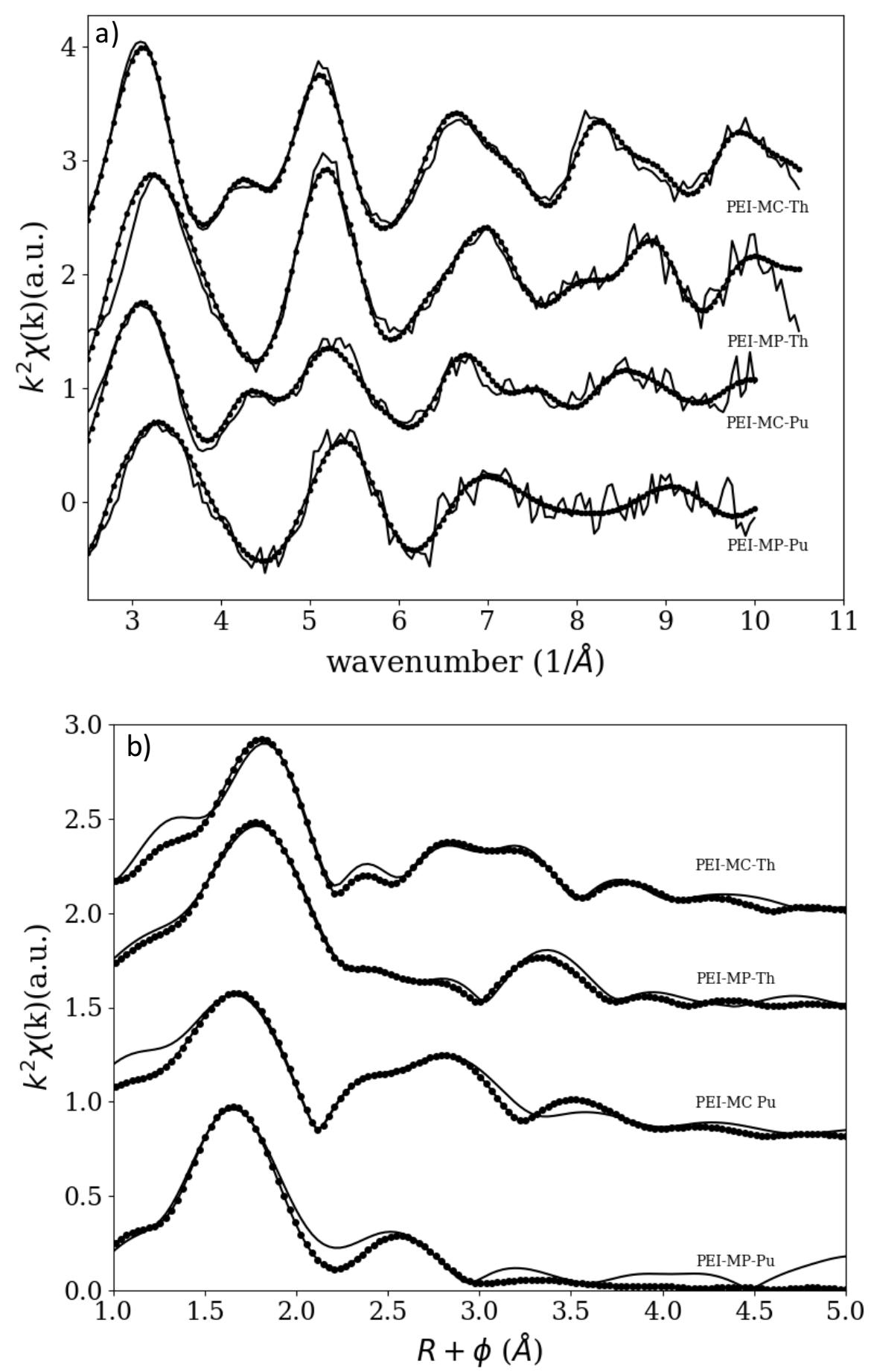

Figure 2ab: EXAFS spectra of the PEI-MP-Pu and PEI-MP-Th complexes under pseudo physiological conditions (a); Corresponding Fourier transform of the EXAFS spectra (b). Solid line = experimental spectrum, dotted line = adjustment. Spectra have been shifted in ordinates for clarity. 

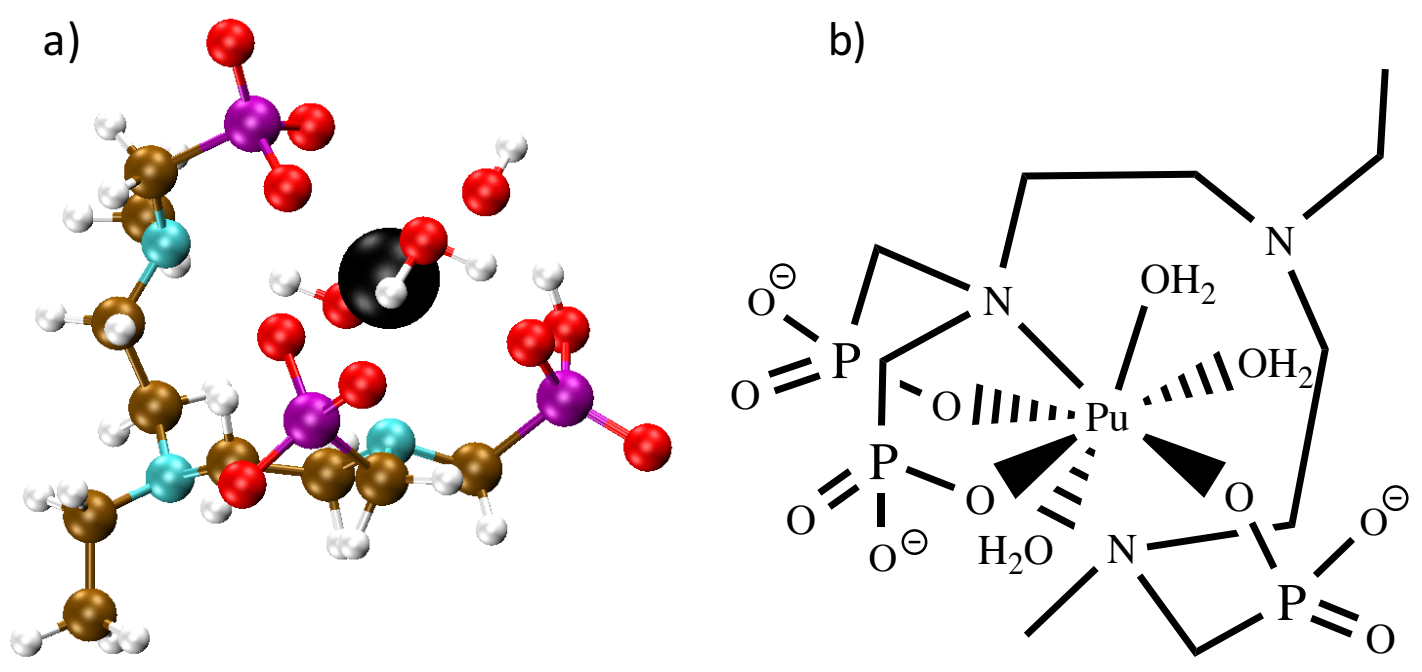

Figure 3ab: Snapshot of PEI-MP*-Pu complex obtained from ab initio MD simulation, with plutonium in black, phosphorus in purple, oxygen in red, nitrogen in blue, carbon in brown and hydrogen in white (a); and schematic drawing of the Pu coordination site in PEI-MP-Pu complex (b). 
PEI-MC*
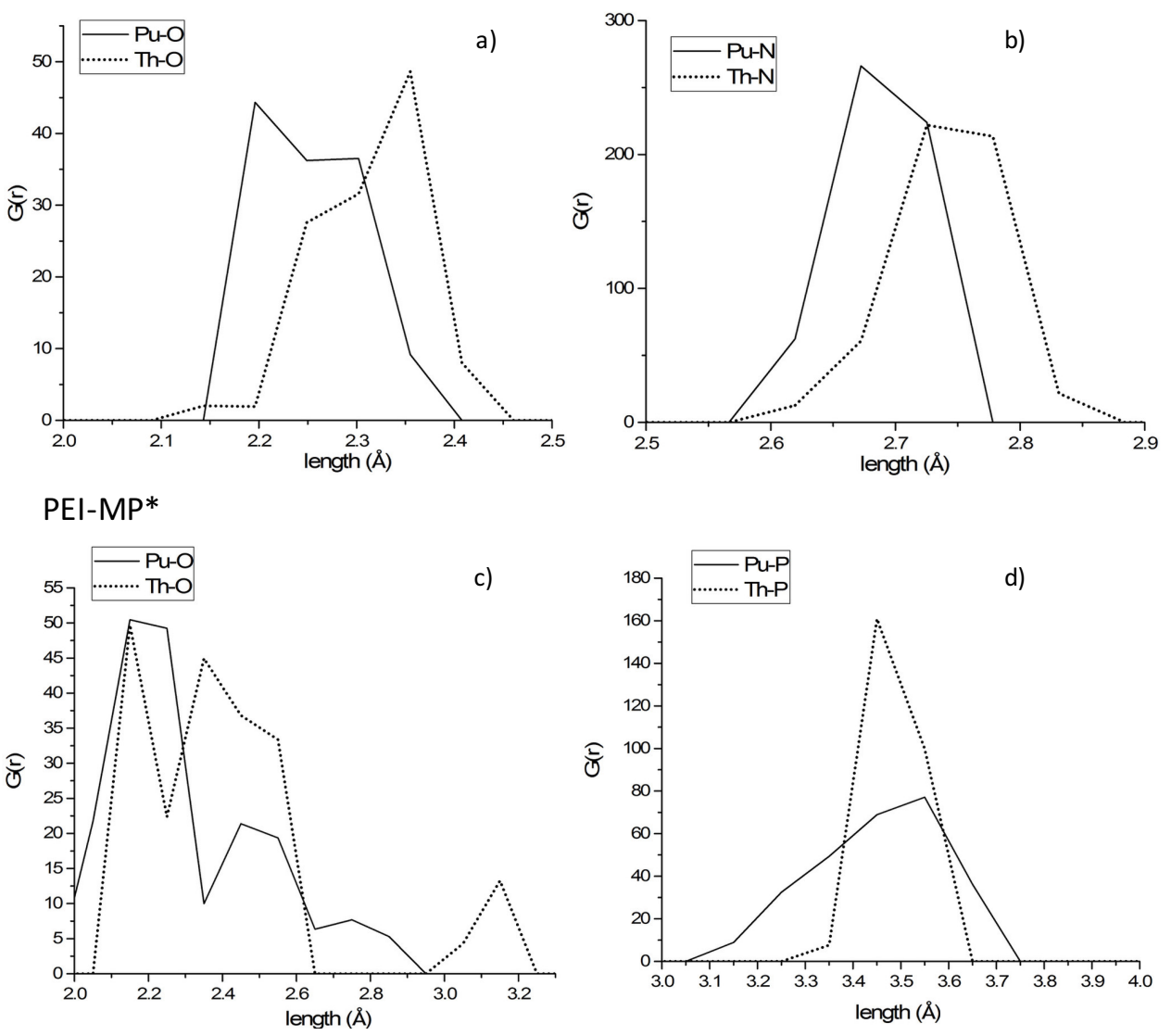

Figure 4abcd: Radial Pair Distribution Functions g(r) of PEI-MC*-M (reproduced from ref. 46 with permission from the Royal Society of Chemistry, $\mathrm{a}, \mathrm{b}$ ) and PEI-MP*-M (c, d) complexes for $\mathrm{M}=$ $\mathrm{Th}(\mathrm{IV}), \mathrm{Pu}(\mathrm{IV})$ obtained from ab initio MD simulations. 

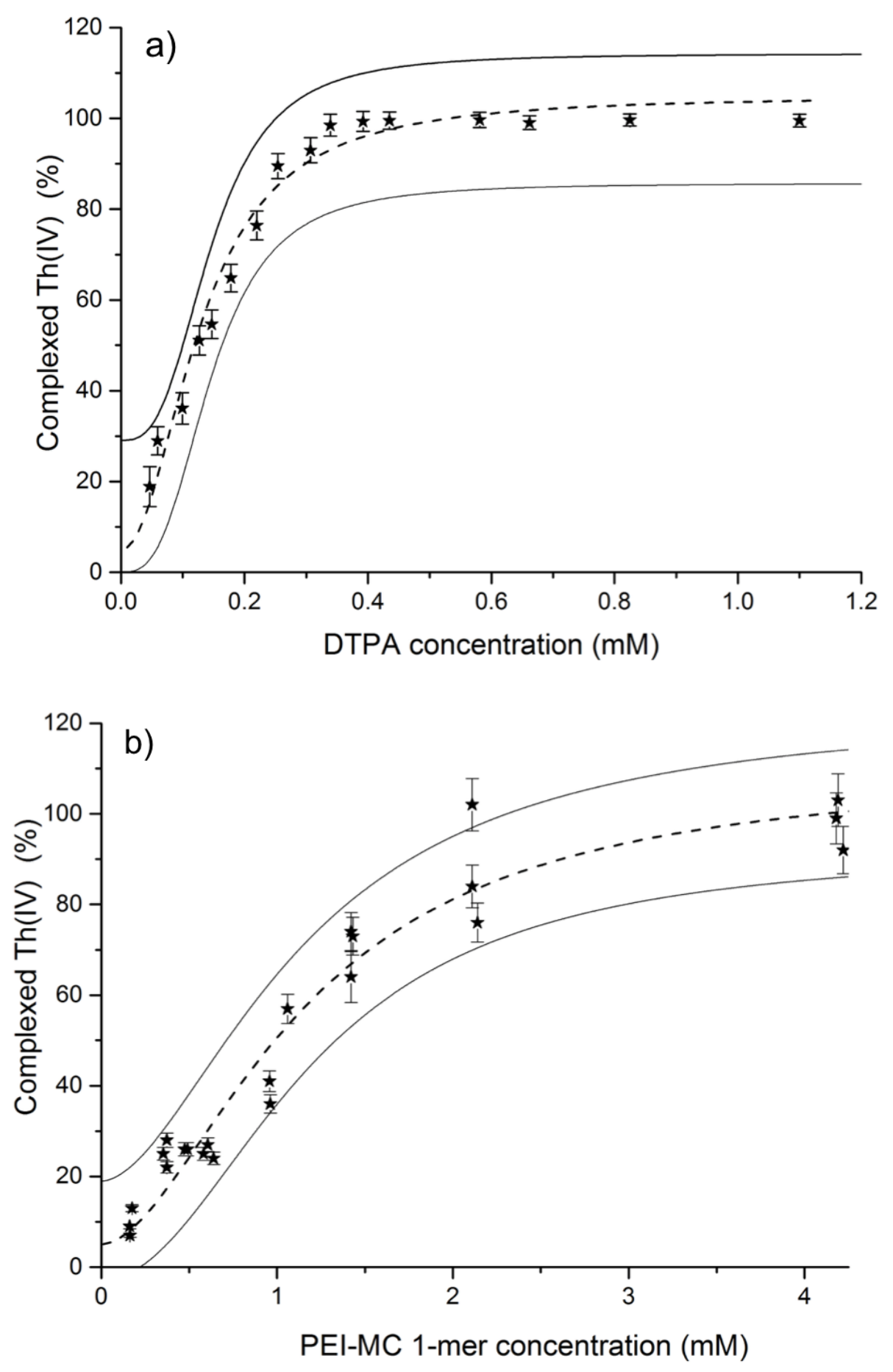


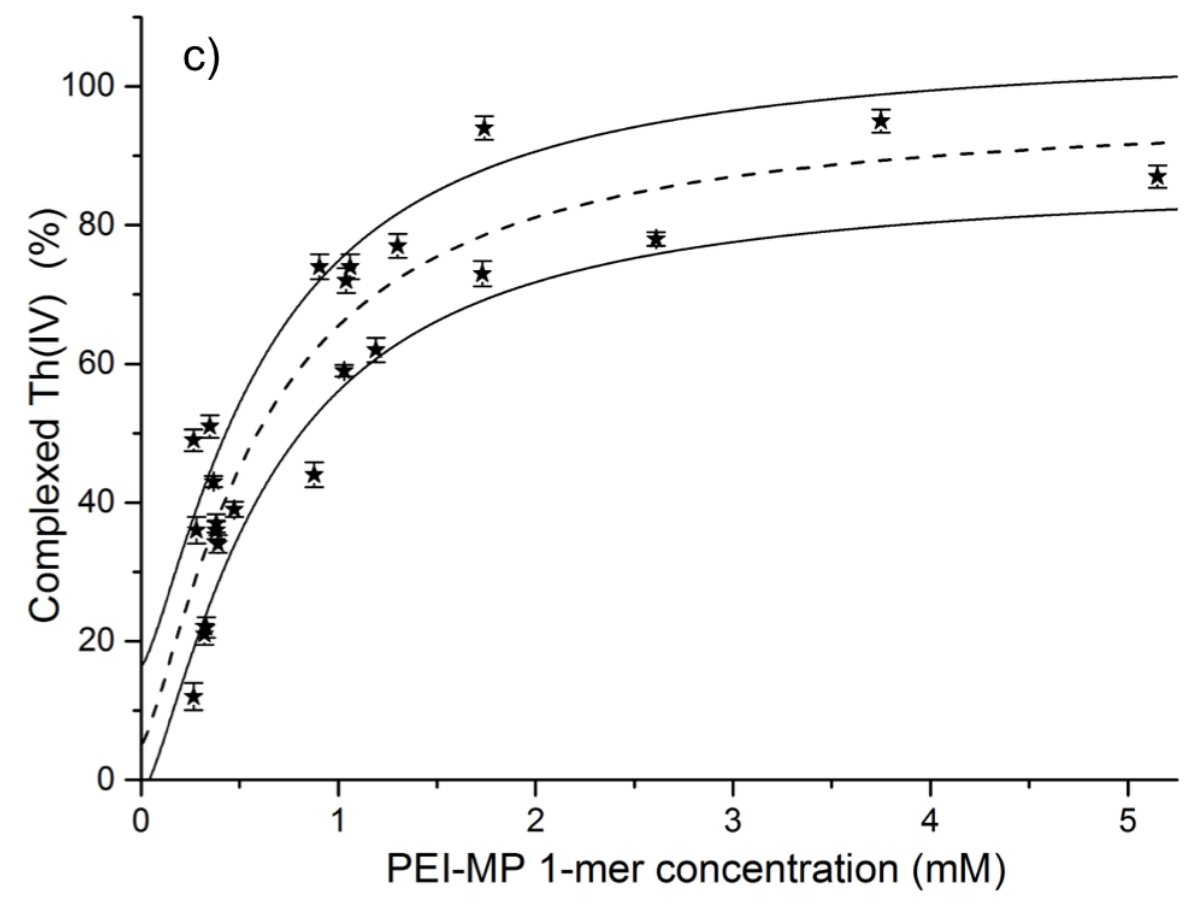

Figure 5abc: Uptake curves representing the complexation rate of $\mathrm{Th}(\mathrm{IV})$ as a function of concentration of DTPA (a), PEI-MC (b) and PEI-MP (c) at pH 7.0. Dash lines = fit with the four-parameter logistic non-linear regression model; Black lines $=95 \%$ confidence interval. 


\section{REFERENCES}

(1) Schwantes, J. M.; Orton, C. R.; Clark, R. A. Analysis of a nuclear accident: fission and activation product releases from the Fukushima Daiichi nuclear facility as remote indicators of source identification, extent of release, and state of damaged spent nuclear fuel. Environ. Sci. Technol. 2012, 46, 8621-8627.

(2) Thakur, P.; Khaing, H.; Salminen-Paatero, S. Plutonium in the atmosphere: A global perspective. J. Environ. Rad. 2017, 39, 175-176.

(3) Morrow, P.E.; Witschi, H.; Vore, M.; Hakkinen, P.E.; Mac Gregor, J.; Anders, M.W.; Willhite, C. Profile in toxicology. Harold Carpenter Hodge (1904-1990). Toxicol. Sci. 2000 53, 157158.

(4) Fattal, E.; Tsapis, F.; Phan, G. Novel drug delivery systems for actinides (uranium and plutonium) decontamination agents, Adv. Drug Delivery Rev., 2015, 90, 40-54.

(5) Leggett, R. W. A Model of the Retention, Translocation and Excretion of Systemic Pu. Health Phys 1985, 49, 1115-1137.

(6) Ansoborlo, E.; Prat, O.; Moisy, P.; Auwer, Den, C.; Guilbaud, P.; Carriere, M.; Gouget, B.; Duffield, J.; Doizi, D.; Vercouter, T.; Moulin, C.; Moulin, V. Actinide speciation in relation to biological processes. Biochimie 2006, 88, 1605-1618.

(7) Bailey, M. R. The New ICRP Model for the Respiratory Tract. Radiat Prot Dosimetry 1994, $53,107-114$.

(8) Wronski, T. J.; Smith, J. M.; Jee, W. S. S. The Microdistribution and Retention of Injected ${ }^{239} \mathrm{Pu}$ on Trabecular Bone Surfaces of the Beagle: Implications for the Induction of Osteosarcoma. Radiat. Res. 1980, 83, 74-89.

(9) Bruenger, F. W.; Stover, B. J.; Stevens, W.; Atherton, D. R. Exchange of ${ }^{239} \mathrm{Pu}$ IV Between Transferrin and Ferritin in Vitro. Health Phys. 1969, 16, 339-340.

(10) Miller, S. C.; Lloyd, R. D.; Bruenger, F. W.; Krahenbuhl, M. P.; Polig, E.; Romanov, S. A. Comparisons of the skeletal locations of putative plutonium-induced osteosarcomas in humans with those in beagle dogs and with naturally occurring tumors in both species. Radiat. Res. 2003, 160, 517-523.

(11) Taylor, G. N.; Lloyd, R. D.; Mays, C. W.; Angus, W.; Miller, S. C.; Shabestari, L.; Hahn, F. F. Plutonium- Or Americium-induced Liver Tumors and Lesions in Beagles. Health Phys. 1991, 61, 337-347.

(12) Wolfang, W. G.; Semmler, M.; Möller, W. Dosimetry and Toxicology of Ultrafine Particles, J. Aerosol Med. 2004, 17, 140-152.

(13) Schubert, J. Treatment of Plutonium Poisoning by Metal Displacement. Science, 1947, 105, 389-390.

(14) Schubert, J. Removal of radioelements from the mammalian body. Annu. rev. nucl. sci. 1955, 5, 369-412.

(15) Hursh, J. B. Effect of BAL on Survival of Rats after Lethal Doses of Polonium. Proc. Soc. Exp. Biol. Med. 1951, 79, 210-212.

(16) Ansoborlo, R.; Amekraz, B.; Moulin, C.; Moulin, V. R.; Taran, F. D. R.; Bailly, T. O.; Burgada, R.; Heng Napoli, M.-H. L. N.; Jeanson, A. L.; Auwer, Den, C.; Bonin, L.; Moisy, P. Review of actinide decorporation with chelating agents. C. R. Chim. 2007, 10, 1010-1019.

(17) Hamilton, J. G.; Scott, K. G. Effect of Calcium Salt of Versene upon Metabolism of Plutonium in the Rat. Proc. Soc. Exp. Biol. Med. 2016, 83, 301-305.

(18) Bonin, L.; Aupiais, J.; Kerbaa, M.; Moisy, P.; Topin, S.; Siberchicot, B. Revisiting actinideDTPA complexes in aqueous solution by CE-ICPMS and ab initio molecular dynamics. RSC $A d v$. 2016, 6, 62729-62741.

(19) Aupiais, J.; Bonin, L.; Auwer, Den, C.; Moisy, P.; Siberchicot, B.; Topin, S. On the use of speciation techniques and ab initio modelling to understand tetravalent actinide behavior in a biological medium: $\mathrm{An}^{\mathrm{IV}}$ DTPA case. Dalton Trans. 2016, 45, 3759-3770.

(20) Durbin, P. W.; Kullgren, B.; Xu, J.; Raymond, K. N. Development of Decorporation Agents for the Actinides. Radiat. Prot. Dosimetry 1998, 79, 433-443.

(21) Taylor, G. N.; Lloyd, R. D.; Boseman, J. J.; Atherton, D. R.; Mays, C. W. Removal of 
Plutonium from Beagles Using Ca-DTPA and Zn-DTPA: Effects of Initial DTPA Injection. Health Phys. 1978, 35, 201-210.

(22) Stevens, W.; Bruenger, F. W.; Atherton, D. R.; Buster, D. S.; Howerton, G. The Retention and Distribution of ${ }^{241} \mathrm{Am}$ and ${ }^{65} \mathrm{Zn}$, Given as DTPA Chelates in Rats and of $\left[{ }^{14} \mathrm{C}\right] \mathrm{DTPA}$ in Rats and Beagles. Radiat. Res. 1978, 75, 397-409.

(23) Stather, J. W.; Smith, H.; Bailey, M. R.; Birchall, A.; Bulman, R. A.; Crawley, F. E. The retention of ${ }^{14} \mathrm{C}$-DTPA in human volunteers after inhalation or intravenous injection. Health Phys. 1983, 44, 45-52.

(24) Mcafee, J. G.; Gagne, G.; Atkins, H. L.; Kirchner, P. T.; Reba, R. C.; Blaufox, M. D.; Smith, E. M. Biological distribution and excretion of DTPA labeled with Tc-99m and In-111. J. Nucl. Med. 1979, 20, 1273-1278.

(25) Grémy, O.; Laurent, D.; Coudert, S.; Griffiths, N. M.; Miccoli, L. Decorporation of Pu/Am Actinides by Chelation Therapy: New Arguments in Favor of an Intracellular Component of DTPA Action. Radiat. Res. 2016, 185, 568-579.

(26) Ramounet-Le Gall, B.; Grillon, G.; Rataeu, G.; Burgada, R.; Bailly, T.; Fritsch, P. Comparative decorporation efficacy of 3,4,3-LIHOPO, 4,4,4-LIHOPO and DTPA after contamination of rats with soluble forms of ${ }^{238} \mathrm{Pu}$ and ${ }^{233} \mathrm{U}$. Radiat. Prot. Dosimetry 2003, 105, 535-538.

Breustedt, B.; Blanchardon, E.; Berard, P.; Fritsch, P.; Giussani, A.; Lopez, M.A.; Luciani, A.; Nosske, D.; Piechowski, J.; Schimmelpfeng, J.; Se randour, A. L. Biokinetic modelling of DTPA decorporation therapy: the conrad approach. Radiat. Prot. Dosimetry 2009, 134, 38-48. Gorden, A. E. V.; Xu, J.; Raymond, K. N.; Durbin, P. Rational design of sequestering agents for plutonium and other actinides. Chem. Rev. 2003, 103, 4207-4282.

Deblonde, G. J.-P.; Sturzbecher-Hoehne, M.; Abergel, R. J. Solution thermodynamic stability of complexes formed with the octadentate hydroxypyridinonate ligand 3,4,3-LI(1,2-HOPO): a critical feature for efficient chelation of lanthanide(IV) and actinide(IV) ions. Inorg. Chem. 2013, 52, 8805-8811.

Kullgren, B.; Jarvis, E. E.; An, D. D.; Abergel, R. J. Actinide chelation: biodistribution and in vivo complex stability of the targeted metal ions. Toxicol. Mech. Methods 2012, 23, 18-26.

Abergel, R. J.; Durbin, P. W., Kullgren, B.; Ebbe, S. N.; Xu, J.; Chang, P. Y.; Bunin, D. I. Blakely, E. A.; Bjornstad, K. A.; Rosen, C. J.; Shuh, D. K.; Raymond, K.N. Biomimetic Actinide Chelators: An Update on the Preclinical Development of the Orally Active Hydroxypyridonate Decorporation Agents 3,4,3-LI(1,2-HOPO) and 5-LIO(Me-3,2- HOPO). Health Phys. 2010, 99, 401-407.

(32) Choi, T. A.; Furimsky, A. M.; Swezey, R.; Bunin, D. I.; Byrge, P.; Iyer, L. V.; Chang, P. Y.; Abergel R. J. In Vitro Metabolism and Stability of the Actinide Chelating Agent3,4,3-LI(1,2HOPO) J. Pharm. sci. 2015, 104, 1832-1838.

(33) Kelley, M. P.; Deblonde, G. J.-P.; Su, J.; Booth, C. H.; Abergel, R. J.; Batista, E. R.; Yang, P. Bond Covalency and Oxidation State of Actinide Ions Complexed with Therapeutic Chelating Agent 3,4,3-LI(1,2-HOPO). Inorg. Chem. 2018, 57, 5352-5363.

(34) Bulman, R. A.; Griffin, R. J.; Russell, A. T. An examination of some complexing agents for ability to remove intracellularly deposited plutonium. Health Phys. 1979, 37, 729-734.

(35) Miller, S. C.; Bruenger, F. W.; Kuswik-Rabiega, G.; Lloyd, R. D. Decorporation of plutonium by oral administration of a partially lipophilic polyaminocarboxylic acid. Health Phys. 1992, 63, 195-197.

(36) Miller, S. C.; Bruenger, F. W.; Kuswik-Rabiega, G.; Liu, G.; Lloyd, R. D. Duration and doserelated effects of an orally administered, partially lipophilic polyaminocarboxylic acid on the decorporation of plutonium and americium. J. Pharmacol. Exp. Ther. 1993, 267, 548-554.

(37) Sueda, K.; Sadgrove, M. P.; Huckle, J. E.; Leed, M. G. D.; Weber, W. M.; Doyle Eisele, M.; Guilmette, R. A.; Jay, M. Orally Administered DTPA Penta-Ethyl Ester for the Decorporation of Inhaled ${ }^{241}$ Am. J. Pharm. Sci. 2014, 103, 1563-1571.

(38) Reddy, J. D.; Cobb, R. R.; Dungan, N. W.; Matthews, L. L.; Aiello, K. V.; Ritter, G.; Eppler, B.; Kirk, J. F.; Abernethy, J. A.; Tomisaka, D. M.; Talton, J. D. Preclinical Toxicology, Pharmacology, and Efficacy of a Novel Orally Administered Diethylenetriaminepentaacetic acid (DTPA) Formulation. Drug Dev. Res. 2012, 73, 232-242.

(39) Wilson, J. P.; Cobb, R. R.; Dungan, N. W.; Matthews, L. L.; Eppler, B.; Aiello, K. V.; Curtis, 
S.; Boger, T.; Guilmette, R. A.; Weber, W.; Doyle Eisele, M.; Talton, J. D. Decorporation of Systemically Distributed Americium by a Novel Orally Administered Diethylenetriaminepentaacetic Acid (DTPA) Formulation in Beagle Dogs. Health Phys. 2015, 108, 308-318.

(40) Phan, G.; Herbet, A.; Cholet, S.; Benech, H.; Deverre, J.-R.; Fattal, E. Pharmacokinetics of DTPA entrapped in conventional and long-circulating liposomes of different size for plutonium decorporation. J. Control. Release 2005, 110, 177-188.

(41) Phan, G.; Le Gall, B.; Grillon, G.; Rouit, E.; Fouillit, M.; Benech, H.; Fattal, E.; Deverre, J. R. Enhanced decorporation of plutonium by DTPA encapsulated in small PEG-coated liposomes. Biochimie 2006, 88, 1843-1849.

(42) Phan, G.; Le Gall, B.; Deverre, J.-R.; Fattal, E.; Benech, H. Predicting Plutonium Decorporation Efficacy after Intravenous Administration of DTPA Formulations: Study of Pharmacokinetic-Pharmacodynamic Relationships in Rats. Pharm. Res. 2006, 23, 2030-2035.

(43) Zeevaart, J. R.; Louw, W. K. A.; Kolar, Z. I.; Kilian, E.; van Rensburg, F. E. J.; Dormehl, I. C. Biodistribution and Pharmacokinetics of Variously Molecular Sized ${ }^{117 \mathrm{~m}} \mathrm{Sn}$ (II)Polyethyleneiminomethyl Phosphonate Complexes in the Normal Primate Model as Potential Selective Therapeutic Bone Agents. Arzneimittelforschung 2011, 54, 340-347.

(44) Oskuee R. K.; Dehshahri , A.; Shier, W. T.; Ramezani, M. Alkylcarboxylate grafting to polyethylenimine: a simple approach to producing a DNA nanocarrier with low toxicity. $J$. Gene. Medicine 2009; 11, 921-932.

(45) Wen, S.; Zheng, F.; Shen, M.; Shi, X. Surface modification and PEGylation of branched polyethyleneimine for improved biocompatibility. J. Appl. Polym. Sci. 2013, 128, 3807-3813.

(46) Lahrouch, F.; Siberchicot, B.; Leost, L.; Aupiais, J.; Rossberg, A.; Hennig, C.; Auwer, Den, C.; Di Giorgio, C. Polyethyleneimine methylenecarboxylate: a macromolecular DTPA analogue to chelate plutonium(IV). Chem. Commun. 2018, 54, 11705-11708.

(47) Lahrouch, F.; Chamayou, A. C.; Creff, G.; Duvail, M.; Hennig, C.; Lozano Rodriguez, M. J.; Auwer, Den, C.; Di Giorgio, C. A Combined Spectroscopic/Molecular Dynamic Study for Investigating a Methyl-Carboxylated PEI as a Potential Uranium Decorporation Agent. Inorg. Chem. 2017, 56, 1300-1308.

(48) Jarvis, N. V.; Zeevaart, J. R.; Wagener, J. M.; Louw, W. K. A.; Dormehl, I. C.; Kilian, E.; Milner, R. J. Metal-ion speciation in blood plasma incorporating the water-soluble polymer, polyethyleneimine functionalised with methylenephosphonate groups, in therapeutic radiopharmaceuticals. Radiochim. Acta 2002, 90, 237-246.

(49) Dormehl, I. C.; Louw, W. K. A.; Milner, R. J.; Kilian, E.; Schneeweiss, F. H. A. Biodistribution and Pharmacokinetics of Variously Sized Molecular Radiolabelled Polyethyleneiminomethyl Phosphonic Acid as a Selective Bone Seeker for Therapy in the Normal Primate Model. Arzneimittelforschung 2011, 51, 258-263.

(50) Lahrouch, F.; Sofronov, O.; Creff, G.; Rossberg, A.; Hennig, C.; Auwer, Den, C.; Di Giorgio, C. Polyethyleneimine methylphosphonate: towards the design of a new class of macromolecular actinide chelating agents in the case of human exposition. Dalton Trans. 2017, 46, 13869-13877.

(51) Krauskopf, K. B. Thorium and rare-earth metals as analogs for actinide elements. Chem. Geol. 1986, 55, 323-335.

(52) Leost, L.; Roques, J.; Van der Meeren, A.; Vincent, L.; Sbirrazzuoli, N.; Hennig, C.; Rossberg, A.; Aupiais, J.; Pagnotta, S.; Auwer, Den, C.; Di Giorgio, C. Towards the development of chitosan nanoparticles for plutonium pulmonary decorporation. Dalton Trans. 2018, 47, $11605-11618$.

(53) Ravel, B.; Newville, M.; IUCr. ATHENA, ARTEMIS, HEPHAESTUS: data analysis for Xray absorption spectroscopy using IFEFFIT. J. Synchrotron Radiat. 2005, 12, 537-541.

(54) Rehr, J. J.; Kas, J. J.; Vila, F. D.; Prange, M. P.; Jorissen, K. Parameter-free calculations of Xray spectra with FEFF9. Phys. Chem. Chem. Phys. 2010, 12, 5503-5513.

(55) Gonze, X.; Amadon, B.; Anglade, P. M.; Beuken, J. M.; Bottin, F.; Boulanger, P.; Bruneval, F.; Caliste, D.; Caracas, R.; Côté, M.; Deutsch, T.; Genovese, L.; Ghosez, P.; Giantomassi, M.; Goedecker, S.; Hamann, D. R.; Hermet, P.; Jollet, F.; Jomard, G.; Leroux, S.; Mancini, M.; Mazevet, S.; Oliveira, M. J. T.; Onida, G.; Pouillon, Y.; Rangel, T.; Rignanese, G. M.; Sangalli, 
D.; Shaltaf, R.; Torrent, M.; Verstraete, M. J.; Zerah, G.; Zwanziger, J. W. ABINIT: Firstprinciples approach to material and nanosystem properties. Comput. Phys. Commun. 2009, 180, 2582-2615. And pseudo potential reference site : https://www.abinit.org/psp-tables

(56) Jollet, F., Torrent, M., Holzwarth, N. Generation of Projector Augmented-Wave atomic data: A 71 element validated table in the XML format. Comput. Phys. Commun. 2014, 185, $1246-$ 1254.

(57) Holzwarth, N. A. W.; Tackett, A. R.; Matthews, G. E. A Projector Augmented Wave (PAW) code for electronic structure calculations, Part I: atompaw for generating atom-centered functions. Comput. Phys. Commun. 2001, 135, 329-347.

(58) Perdew, J. P.; Burke, K.; Ernzerhof, M. Generalized Gradient Approximation Made Simple. Phys. Rev. Lett. 1996, 77, 3865-3868.

(59) Jomard, G.; Amadon, B.; Bottin, F.; Torrent, M. Structural, thermodynamic, and electronic properties of plutonium oxides from first principles. Phys. Rev. B 2008, 78, 075125-1-07512511.

(60) Von Harpe, A.; Petersen, H.; Li, Y.; Kissel, T. Characterization of commercially available and synthesized polyethylenimines for gene delivery. J. Controlled Release, 2000, 69, 309-322

(61) Szabó, Z.; Toraishi, T.; Mallet, V.; Grenthe, I. Solution coordination chemistry of actinides: Thermodynamics, structure and reaction mechanisms. Coord. Chem. Rev., 2006, 250, 784-815.

(62) Andreev, G.; Budantseva, N.; Sokolova, M.; Tananaev, I.; Myasoedov, B. Interaction of Transuranium Elements with Biologically Important Ligands: Structural and Spectroscopic Evidence for Nucleotide Coordination to Plutonium. Inorg. Chem. 2009, 48, 2343-2345.

(63) Nelson, A.-G. D.; Bray, T. H.; Stanley, F. A.; Albrecht-Schmitt T. E. Periodic Trends in Actinide Phosphonates: Divergence and Convergence between Thorium, Uranium, Neptunium, and Plutonium Systems. Inorg. Chem. 2009, 48, 4530-4535.

(64) Santschi, P. H.; Murray, J. W.; Baskaran, M.; Benitez-Nelson, C. R.; Guo, L. D.; Hung, C. C.; Lamborg, C.; Moran, S. B.; Passow, U.; Roy-Barman, M. Thorium speciation in seawater. Mar. Chem. 2006, 100, 250-268.

(65) Langmuir, D.; Herman, J. S. The mobility of thorium in natural waters at low temperatures. Geochim. Cosmochim. Acta 1980, 44, 1753-1766. 


\section{For Table of Contents Only}

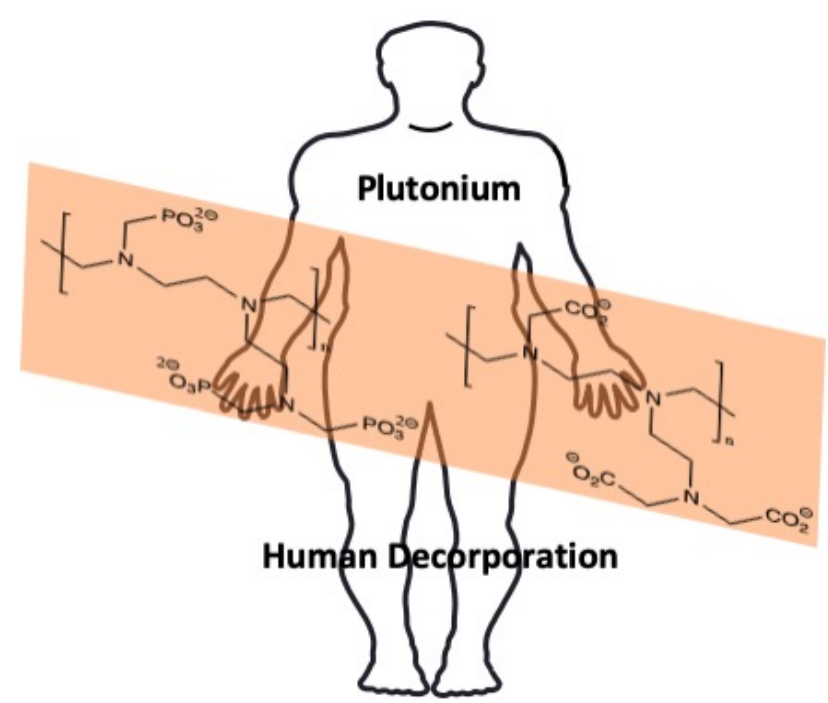

Discussion on alternative polyethyleneimine based platforms that may represent a breakthrough in the field of plutonium decorporation field. Combination of $a b$ initio Molecular Dynamics and Extended X-ray Absorption Fine Structure to clarify the actinide complexation mechanism. 